\title{
Analysis of risk factors for early mortality and multiorgan failure after pericardiectomy for constrictive pericarditis
}

Jing-bin Huang ( $\nabla$ hjb010222@163.com )

PEOPEL,S HOSPITAL OF GUANGXI ZHUANG AUTONOMOUS REGION

Zhao-ke Wen

PEOPEL,S HOSPITAL OF GUANGXI ZHUANG AUTONOMOUS REGION

Wei-jun Lu

PEOPEL,S HOSPITAL OF GUANGXI ZHUANG AUTONOMOUS REGION

Chang-chao Lu

PEOPEL,S HOSPITAL OF GUANGXI ZHUANG AUTONOMOUS REGION

Xian-ming Tang

PEOPEL,S HOSPITAL OF GUANGXI ZHUANG AUTONOMOUS REGION

\section{Research Article}

Keywords: Constrictive pericarditis, pericardiectomy, mortality, multiorgan failure, risk factors

Posted Date: December 8th, 2020

DOI: https://doi.org/10.21203/rs.3.rs-115785/v1

License: (9) This work is licensed under a Creative Commons Attribution 4.0 International License. Read Full License 


\section{Abstract}

Background:. The operative mortality of pericardiectomy is still high. This prospective study was to determine the risk factors for early mortality and multiorgan failure.

Methods: We prospectively observe patients undergoing pericardiectomy from January 2009 to June 2020 at our hospital. Radical pericardiectomy was performed via sternotomy. Histopathologic studies of pericardum tissue from every patient was done. All survivors were monitored to the end date of the study.

Results: 92 consecutive underdoing pericardiectomy for constrictive pericarditis were included in the study. Postoperatively ,CVP decreased significantly, and LVED and LVEF improved significantly. The overall mortality rate was $5.4 \%$. The common postoperative complications inclued acute renal injury $\triangle 27.2 \% \bigotimes$, low cardiac output syndrome $(10.9 \%)$, and multiorgan failure (8.7\%). Analysis of risk factor showed that D2 (fluid balance of the second day following operation) was associated with decreased early mortality and decreased multiorgan failure. In this series from Guagxi, China, characteristic histopathologic features of tuberculosis $₫ 60 / 92,65.2 \% \rrbracket$ of pericardium were the most common histopathologic findings, and 32 patients (32/92,34.8\%) had the histopathologic findings of chronic nonspecific inflammatory changes. The functional status of the patients improved after pericardiectomy, 6 months postoperatively 85 survivors were in class I $(85 / 87,97.7 \%)$ and 2 in class II $(2 / 87,2.3 \%)$.

Conclusions: Our results show that pericardiectomy is an effective procedure in the treatment of constrictive pericarditis Early surgical intervention is advocated. Improvement of surgical technique and intraoperative and perioperative management can decrease mortality and morbidity.

\section{Introduction}

Constrictive pericarditis is a progressive and disabling disease and arises as a result of the fibrous thickening and calcification of the pericardium due to chronic inflammatory changes from various injuries that impairs diastolic filling, reduces cardiac output, and ultimately leads to left and right heart failure. Patients with constrictive pericarditis undergo pericardiectomy with symptomatic improvement in over $90 \%$ of them after the procedure. [1-3] While the operative mortality risk of pericardiectomy is still high and ranges between $5 \%$ and $20 \% .[4,5]$

We hypothesized that improvement in the perioperative management and operative skills can decrease the operative mortality risk of pericardiectomy.

This prospective study was conducted to determine the risk factors for early mortality and multiorgan failure (MOF) and to decrease the operative mortality risk of pericardiectomy.

\section{Patients And Methods}

\subsection{Patients}


We prospectively observe patients who underwent pericardiectomy for constrictive pericarditis from January 2009 to June 2020 at our hospital.

The diagnosis of constrictive pericarditis was confirmed by clinical presentation, echocardiographic study, chest computed tomographic (CT) scan and cardiac catheterization, as needed. (Figure 1, Figure 2) [6-9]

\subsection{Surgical Technique}

Radical pericardiectomy was performed via sternotomy between the two phrenic nerves and from the great vessels to the basal aspect of the heart. In cases of high risk of coronary artery or myocardial damage, or severe bleeding, the pericardium over the right atrium or superior and inferior venae cavae was left intact. The primary intention was pericardiectomy without Cardiopulmonary bypass (CPB).

Perioperative death was defined as death within 30 days of the operation or during the same hospital admission.

AKI was defined according to the Acute Kidney Injury Network (AKIN) classification, using serum creatinine and urine output as criteria for the evaluation of renal function.

\subsection{Histopathologic studies}

Histopathologic studies of pericardum tissue from every patient was done. The diagnosis of tuberculosis was confirmed on the basis of clinical findings and histopathologic features, including the presence of typical granuloma and caseous necrosis, acid-fast bacilli in Ziel-Nelson tissue staining, and bacteriologic studies using the polymerase chain reaction (PCR) test on the pericardial fluid or tissue for evidence of mycobacterium tuberculosis.

\subsection{Follow-up}

All survivors discharged from hospital were monitored to the end date of the study. All patients at the outpatient department were examined with electrocardiogram, X-ray chest film and echocardiogram, once every 3 to 6 months. At the last follow-up, the patients were contacted by telephone or micromassage or interviewed directly at the outpatient department.

The experiment protocol for involving humans was in accordance to national guidelines and was approved by the Medical Ethics Committee of The People's Hospital of Guangxi Zhuang Autonomous Region and The Medical Ethics Committee of The People's Hospital of Guangxi Zhuang Autonomous Region gave the authors approval to waive the need for patient consent for publishing data in the study about the patients.

\subsection{Statistical analysis}


Continuous variables are reported as means \pm SE. Survival rates were estimated using the Kaplan-Meier method. The chi-square test, the Kruskal-Walls test or the Wilcoxon rank-sum test, as appropriate, to be used to evaluate relationships between the preoperative variables, and selected intraoperative and postoperative variables. The relationships with perioperative risk factors were assessed by means of contingency table methods and logistic regression analysis. To explore the simultaneous effects of perioperative characteristics on early death, variables that were significant at the 0.1 level in univariate analysis were included in a multivariate logistic regression model. $P$ values less than 0.05 were considered to be statistically significant. All analyses were performed using IBM SPSS version 24.0 software (IBM SPSS Inc., USA).

\section{Results}

\subsection{Operative results}

92 consecutive underdoing pericardiectomy for constrictive pericarditis were included in the study (Table 1.). 44 patients $(44 / 92,47.8 \%)$ had constrictive pericarditis associated with pericardial effusion.

Cardiopulmonary bypass was performed in 8 patients $(8 / 92,8.7 \%)$ with concomitant valve replacement. Only 2 patients underwent cardiac catheterization.

Table 1. Preoperative Characteristics of the Patients $₫ n=92 \rrbracket$ 


\begin{tabular}{|ll|}
\hline Variable & Value \\
\hline female / male (n) & $59 / 33$ \\
\hline age (years) & $52.83 \pm 1.56$ (range,17.0 to 74.0) \\
\hline weight before diuresis $(\mathrm{kg})$ & $55.97 \pm 0.94$ (range,36.0 to 81.0) \\
\hline weight after diuresis $(\mathrm{kg})$ & $53.0 \pm 0.74$ (range,34.0to 72.0) \\
\hline NYHA class & \\
\hline II & $53(57.6 \%)$ \\
\hline III & $38(41.3 \%)$ \\
\hline IV & $1(1.1 \%)$ \\
\hline cachexia(n) & $3(3.3 \%)$ \\
\hline pulmonary tuberculosis(n) & $2(2.2 \%)$ \\
\hline rheumatic heart disease(n) & $3(3.3 \%)$ \\
\hline infective endocarditis(n) & $1(1.1 \%)$ \\
\hline valvular heart disease(n) & $3(3.3 \%)$ \\
\hline coronary heart disease(n) & $3(3.3 \%)$ \\
\hline pleural effusion(n) & $8(8.7 \%)$ \\
\hline preoperative LVED(mm) & $40.82 \pm 0.36($ range,29.0 to 49.0) \\
\hline preoperative LVEF(mm) & $0.62 \pm 0.01($ range,0.51 to 0.74) \\
\hline aortic insufficiency $(\mathrm{n})$ & $6(6.5 \%)$ \\
\hline mitral regurgitation(n) & $8(8.7 \%)$ \\
\hline tricuspid regurgitation(n) & $5(5.4 \%)$ \\
\hline thickened pericardium $(\mathrm{n})$ & $91(98.9 \%)$ \\
\hline pericardial effusion(n) & $44(47.8 \%)$ \\
\hline Pericardial calcification(n) & $15(16.3 \%)$ \\
\hline
\end{tabular}

Postoperatively ,CVP decreased statistically significantly $\triangle P=0.000 \bigotimes$, and LVED and LVEF improved

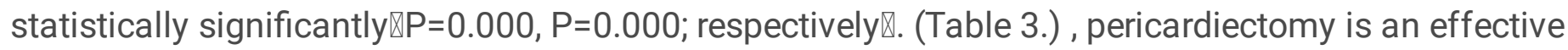
procedure in the treatment of constrictive pericarditis.

The overall mortality rate in this series was 5.4\% (5/92), and the 5 patients all died of multiorgan failure (MOF). All patients with multiple organ failure $(n=5)$ had acute renal injury, which accounted for $20 \%$ $(5 / 25)$ of patients with acute renal injury. (Table 2. and Table 4.) 
The common early postoperative complications inclued acute renal injury $₫ 25 / 92,27.2 \% \bigotimes$, low cardiac output syndrome (10/92, 10.9\%), and multiorgan failure (8/92, 8.7\%). (Table 4.)

The functional status of the patients improved after pericardiectomy. 53 of the 92 patients $(57.6 \%)$ had been in NYHA class II , 38 of $92(41.3 \%)$ in class III, and 1 of $92(1.1 \%)$ in class IV before the operation, but 6 months postoperatively 85 survivors were in class I (85/87, 97.7\%) and 2 in class II $(2 / 87,2.3 \%)$.

Table 2.Operative Data $₫ n=92 \rrbracket$

\begin{tabular}{|c|c|}
\hline Variable & Value \\
\hline mean intubation time $₫$ hours $\rrbracket$ & $75.89 \pm 8.69$ (range, 3.0 to 336.0 ) \\
\hline ICU retention time (days) & $5.32 \pm 0.53$ (range, 1.0 to 32.0 ) \\
\hline hospitalized time after surgery (days) & $16.05 \pm 1.16$ (range, 1.0 to 99.0 ) \\
\hline post-operative CVP( $\mathrm{mmHg})$ & $11.62 \pm 0.31$ (range,5.to 20 ) \\
\hline D0 fluid balance $(\mathrm{ml})$ & $-1269.5 \pm 87.5($ range,-3100 to 500$)$ \\
\hline D1 fluid balance (ml) & $-777.5 \pm 124.8$ (range,-4320to 1830 ) \\
\hline D2 fluid balance $(\mathrm{ml})$ & $-777.6 \pm 73.1$ (range,-2700 to 700 ) \\
\hline Postoperative chest drainage $(\mathrm{ml})$ & $932.9 \pm 57.4$ (range, 150 to 2300 ) \\
\hline post-operative LVED( mm ) & $42.7 \pm 0.3$ (range, 36.0 to 49.0 ) \\
\hline post-operative $\operatorname{LVEF}(\mathrm{mm})$ & $0.66 \pm 0.01$ (range, 0.52 to 0.79 ) \\
\hline
\end{tabular}

D0 fluid balance $(\mathrm{ml})=$ fluid balance on operation day=iuput-output; D1 fluid balance $(\mathrm{ml})=$ fluid balance of the first day following operation; D2 fluid balance $(\mathrm{ml})$ = fluid balance of the second day following operation; the second day

Table3. Operative Results

\begin{tabular}{|llll|}
\hline clinical data & preoperative & post-operative & P value \\
$\operatorname{CVP}(\mathrm{mmHg}) \llbracket n=92 \rrbracket$ & $20.42 \pm 0.50$ & $11.62 \pm 0.31$ & 0.000 \\
$\operatorname{LVED}(\mathrm{mm}) \llbracket n=88 \rrbracket$ & $40.82 \pm 0.37$ & $42.73 \pm 0.34$ & 0.000 \\
$\operatorname{LVEF}(\mathrm{mm})(\mathrm{n}=88)$ & $0.62 \pm 0.01$ & $0.66 \pm 0.01$ & 0.000 \\
\hline
\end{tabular}

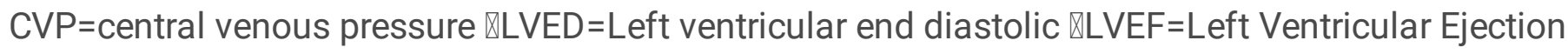
Fractions .

Table 4. Postoperative Complications $(n=92)$ 


\begin{tabular}{|c|c|}
\hline complication & $\mathrm{n} \otimes \% \bigotimes$ \\
\hline low cardiac output syndrome(n) & $10 \otimes 10.9 \% \rrbracket$ \\
\hline acute renal injury(n) & $25 \llbracket 27.2 \% \rrbracket$ \\
\hline multiorgan failure(n) & $8 \rrbracket 8.7 \% \rrbracket$ \\
\hline long-term intubation $₫ 48 \mathrm{~h}(\mathrm{n})$ & $44 \rrbracket 47.8 \% \rrbracket$ \\
\hline empyema(n) & $1 \otimes 1.1 \% \rrbracket$ \\
\hline hepatic failure(n) & $1 \rrbracket 1.1 \% \rrbracket$ \\
\hline respiratory failure(n) & $3 \rrbracket 3.3 \% \rrbracket$ \\
\hline ventricular fibrillation(n) & $2 \rrbracket 2.2 \% \rrbracket$ \\
\hline
\end{tabular}

\subsection{Analysis of risk factors for early mortality and multiorgan failure}

\subsubsection{Analysis of risk factors for early mortality}

Univariate analysis of potential risk factor for early mortality showed that Weight after diuresis was associated with decreased early mortality $(\mathrm{OR}=0.852, \mathrm{P}=0.020)$.

Both univariate and multivariate analyses of risk factor for early mortality showed that D2 (fluid balance of the second day following operation) was a independent predictor of decreased early mortality. ( Table 5.)

Both univariate and multivariate analyses of risk factor for early mortality showed that D1 (fluid balance of the first day following operation) was a independent predictor of increased early mortality. ( Table 5.)

\subsubsection{Analysis of risk factors for multiorgan failure}

Univariate analysis of potential risk factor for multiorgan failure showed that postoperative chest drainage were associated with increased multiorgan failure $(\mathrm{OR}=1.001, \mathrm{P}=0.042)$.

Both univariate and multivariate analyses of risk factor for multiorgan failure showed that D2 (fluid balance of the second day following operation) was a independent predictor of decreased multiorgan failure.

Table 5. Analysis of risk factors for early mortality and multiorgan failure 


\begin{tabular}{|c|c|c|c|}
\hline Model & $\mathrm{OR}$ & $95 \% \mathrm{Cl}$ & $P$ value \\
\hline \multicolumn{4}{|c|}{ Univariate analysis of risk factors for mortality } \\
\hline D1 fluid balance (ml) & 1.001 & $(1.000-1.002)$ & 0.038 \\
\hline D2 fluid balance $(\mathrm{ml})$ & 0.998 & $(0.997-1.000)$ & 0.015 \\
\hline weight after diuresis $(\mathrm{kg})$ & 0.852 & $(0.744-0.975)$ & 0.020 \\
\hline \multicolumn{4}{|c|}{ Multivariate analysis of risk factors for mortality } \\
\hline D1 fluid balance $(\mathrm{ml})$ & 1.003 & $(1.000-1.005)$ & 0.034 \\
\hline D2 fluid balance $(\mathrm{ml})$ & 0.996 & $(0.992-0.999)$ & 0.017 \\
\hline weight after diuresis $(\mathrm{kg})$ & 1.103 & $(0.942-1.293)$ & 0.224 \\
\hline \multicolumn{4}{|c|}{ Univariate analysis of risk factors for multiorgan failure } \\
\hline D2 fluid balance $(\mathrm{ml})$ & 0.999 & $(0.998-1.000)$ & 0.002 \\
\hline Postoperative chest drainage (ml) & 1.001 & $(1.000-1.002)$ & 0.042 \\
\hline weight before diuresis $(\mathrm{kg})$ & 0.925 & $(0.861-0.993)$ & 0.032 \\
\hline \multicolumn{4}{|c|}{ Multivariate analysis of risk factors for multiorgan failure } \\
\hline D2 fluid balance $(\mathrm{ml})$ & 0.999 & $(0.998-1.000)$ & 0.042 \\
\hline postoperative chest drainage $(\mathrm{ml})$ & 1.000 & $(0.999-1.001)$ & 0.796 \\
\hline weight before diuresis $(\mathrm{kg})$ & 0.943 & $(0.867-1.027)$ & 0.178 \\
\hline
\end{tabular}

D0 fluid balance= fluid balance on operation day; D1 fluid balance= fluid balance of the first day following operation; D2 fluid balance= fluid balance of the second day following operation.

\subsection{Histopathologic findings in the series from Guagxi, China}

In this series from Guagxi, China, characteristic histopathologic features of tuberculosis $₫ 60 / 92,65.2 \%$ of pericardium were the most common histopathologic findings, and 32 patients (32/92,34.8\%) had the histopathologic findings of chronic nonspecific inflammatory changes. (Figure 3, Figure 4)

\subsection{Follow-up results}

All the 87 survivors discharged from hospital were monitored to the end date of the study and the followup was $100 \%$ completed $(n=87)$. The mean duration of follow-up was $52.4 \pm 4.5$ months (range, 2 to 138 ), no late death and reoperation occurred. Latest follow-up data showed that 85 survivors were in NYHA class I (85/87, 97.7\%) and 2 in class II $(2 / 87,2.3 \%)$.

\section{Discussion}


Constrictive pericarditis is defined as the chronic fibrous thickening of the wall of the pericardial sac, which results in abnormal diastolic filling. Surgical pericardiectomy is extremely effective and possibly restorative for the heart failure, while it is particularly challenging because of the increased risk of right heart failure. [10-14]

Surgical removal of the pericardium is associated with a operative mortality rate of $5 \%$ to $20 \%$ in various large series. Myocardial atrophy after prolonged constriction, residual constriction, or a concomitant myocardial process can lead to prolonged cardiac failure despite successful pericardiectomy. [15-18]

\subsection{Improvement of surgical technique}

In order to avoid pulmonary edeama and the heart is damaged due to excessive expansion because a large amount of tissue fluid flows back the heart and the lung, the pericardium was decorticated in the following order: left ventricular outflow tract - apex of heart - right ventricular outflow tract - right ventricle - superior and inferior vena cava entrance - pericardium diaphragm surface.

If the pericardium calcification is serious and closely adheres to the myocardium, it is difficult to completely peel off the pericardium. The local "\#"shaped incision is used to release the pericardium. [1921]

\subsection{Mortality and Low cardiac output syndrome}

Low cardiac output syndrome was the most common cause of death during the early postoperative phase in the present study. This low cardiac output state after pericardiectomy might have been due to incomplete pericardiectomy. Nonetheless, postoperative transient interstitial edema, could have had an impotant effect. Correct and effective perioperative management is of great significance to reduce the operative mortality. After pericardiectomy, the heart is in a high volume load state in a short period of time.At this time, usage of large amount of diuretics becomes feasible and necessary, which is also one of the key points for further improvement of cardiac function after operation. [22-24]

The following measures are important to decrease the operative mortality risk of pericardiectomy. (1) strengthen nutrition before operation to improve general condition, intermittently input of plasma or albumin to increase colloidal osmotic pressure, and Aggressive diuresis is completed to reduce tissue edema to reduce the amount of blood returning the heart postoperatively. (2) During and after the operation, carry out continuous invasive monitoring of arterial and venous pressure. The amount of crystal input is strictly controlled. Fresh frozen plasma and albumin are properly imported. Aggressive diuresis is performed in order to avoid further aggravating the burden on the heart and causing heart failure. Regular anti tuberculosis treatment is given to patients with tuberculosis. (3) After pericardial stripping off and release of superior and inferior vena cava, active diuresis, cardiotonic drugs and vasoactive drugs should be applied. The application time of vasoactive drugs should be appropriately prolonged and gradually reduced. (4) After the operation, the infusion volume and speed should be strictly controlled, and the negative balance should be maintained. Routinely use vasoactive drugs, such 
as dopamine, dobutamine, nitroprusside, etc.; rationally use diuretics. Due to the long-term compression of the thickened pericardium and myocardial ischemia, the heart denaturates and atrophies, and the heart has poor adaptability to the changes of hemodynamics. After the heart is released, a large amount of blood flows back and the load of the heart increases, which leads to the occurrence of heart failure or malignant arrhythmia, and often leads to cardiac arrest. The postoperative low-output state gradually improved in most of patients. $[25,26]$

\subsection{Pathological Discussion}

In this series from Guagxi, China, characteristic histopathologic features of tuberculosis of pericardium $\triangle 60 / 92,65.2 \% \bigotimes$ were the most common histopathologic findings, following by the chronic nonspecific inflammatory changes $(32 / 92,34.8 \%)$ (Table 6).

Constrictive pericarditis exhibits a heterogeneous pattern and arises from different causes, depending on the geographic area from which it is reported. $38 \%$ to $83 \%$ of the cases of constrictive pericarditis are still caused by tuberculosis in developing countries. Table 6 . shows the prevalence of causal factors for constrictive pericarditis in treatment centers in the United States, Spain, Iran and China. [27, 28]

Table 6. Prevalence of Causal Factors for Constrictive Pericarditis in Treatment Centers in the United States, Spain, Iran and China

\begin{tabular}{|lllll|}
\hline Cause & $\begin{array}{l}\text { Cleveland } \\
\text { Clinic(\%) }\end{array}$ & $\begin{array}{l}\text { Barcelona1 } \\
(\%)\end{array}$ & $\begin{array}{l}\text { Iran } \\
(\%)\end{array}$ & $\begin{array}{l}\text { Guangxi, } \\
\text { China(\%) }\end{array}$ \\
\hline Idiopathic disease & 46 & 46.7 & 60 & 34.8 \\
\hline Tuberculosis & 3.7 & 6.7 & 22.2 & 65.2 \\
\hline Post-cardiotomy & 37 & 6.7 & 4.4 & 0 \\
\hline Radiation therapy & 9 & 13.3 & 0 & 0 \\
\hline Malignancy & 0 & 26.7 & 4.4 & 0 \\
\hline End-stage renal diseas & 0 & 0 & 8.9 & 0 \\
\hline Miscellaneous & 4.3 & 0 & 2.2 & 0 \\
\hline
\end{tabular}

\section{Conclusions}

Our results show that pericardiectomy is an effective procedure in the treatment of constrictive pericarditis for it yields excellent functional outcomes. Early surgical intervention is advocated, as constrictive pericarditis is a progressive disease. Improvement of surgical technique and intraoperative and perioperative management can decrease mortality and morbidity. 


\section{Abbreviations}

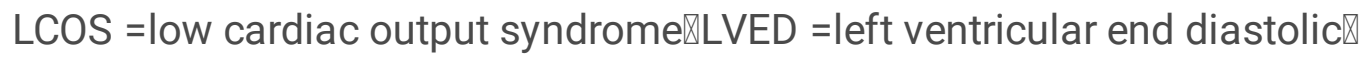

$\mathrm{CT}=$ chest computed tomographic $\mathbb{C P B}=$ cardiopulmonary bypass;

$\mathrm{CO}=$ cardiac output; $\mathrm{Cl}=$ cardiac index; $\mathrm{ICU}=$ intensive care unit;

$\mathrm{MOF}=$ multiple organ failure $; \mathrm{ECMO}=$ Extracorporeal Membrane Oxygenation.

AKIN=Acute Kidney Injury Network》

\section{Declarations}

\section{Ethics approval and consent to participate}

\section{Statements}

The experiment protocol for involving humans was in accordance to national guidelines and was approved by the Medical Ethics Committee of The People's Hospital of Guangxi Zhuang Autonomous Region .

The Medical Ethics Committee of The People's Hospital of Guangxi Zhuang Autonomous Region $2020-10-12$

\section{Statements}

The Medical Ethics Committee of The People's Hospital of Guangxi Zhuang Autonomous Region gave the authors approval to waive the need for patient consent for publishing data in the study about the patients.

The Medical Ethics Committee of The People's Hospital of Guangxi Zhuang Autonomous Region 2020-10-12

\section{Consent for publication}

Written informed consent for publication was obtained from all participants.

3. Availability of data and materials The datasets generated and/or analysed during the current study are available from the corresponding author on reasonable request. 4 . Competing interests

The authors declare they have no conflict of interest regarding the publication of this editorial.

5. Funding 
This work was supported by the Natural Science Foundation of China (grant code: 81360014), the Natural Science Foundation of Guangxi (grant code: 2014GXNSFAA118234), the Guangxi key scientific and technological project (grant code: 2013BC26236), and the Projects in Guangxi Health Department (grant code: GZPT13-27).

\section{Authors' contributions}

Jing-bin Huang MD and Zhao-ke Wen MD contributed to the writing, reviewing and editing of the manuscript.

Wei-jun Lu MD, Chang-chao Lu MD, and Xian-ming Tang MD were responsible for the conceptualization of the editorial and contributed to the writing, reviewing and editing of the manuscript.

\section{Acknowledgements}

The authors would like to thank Dr Li, Department of Cardiothoracic Surgery, The People's Hospital of Guangxi Zhuang Autonomous Region, for his helpful comments.

\section{References}

1. Acharya A, Koirala R, Rajbhandari N, et al. Anterior Pericardiectomy for Postinfective Constrictive Pericarditis: Intermediate-Term Outcomes. Ann Thorac Surg. 2018;106(4):1178-1181.

2. Depboylu BC, Mootoosamy P, Vistarini N, et al. Surgical Treatment of Constrictive Pericarditis. Tex Heart Inst J. 2017;44(2):101-106.

3. Melo DTP, Nerbass FB, Sayegh ALC, et al. Impact of pericardiectomy on exercise capacity and sleep of patients with chronic constrictive pericarditis. PLoS One. 2019;14(10):e0223838.

4. Mori M, Mullan CW, Bin Mahmood SU, et al. US National Trends in the Management and Outcomes of Constrictive Pericarditis: 2005-2014. Can J Cardiol. 2019;35(10):1394-1399.

5. Calderon-Rojas R, Greason KL, King KS, et al. Tricuspid Valve Regurgitation in Patients Undergoing Pericardiectomy for Constrictive Pericarditis [published online ahead of print, 2020. Semin Thorac Cardiovasc Surg. 2020;51043-0679(20)30052-6.

6. Gatti G, Fiore A, Ternacle J, et al. Pericardiectomy for constrictive pericarditis: a risk factor analysis for early and late failure. Heart Vessels. 2020;35(1):92-103.

7. Wei S, Zhang L, Cui H, et al. Surgery for Patients with Radiation-Induced Constrictive Pericarditis. Heart Surg Forum. 2019;22(6):E466-E469.

8. Armstrong JL, Wojnarski CM, Choi AY, et al. Constrictive Pericarditis After Lung Transplantation. Transplantation. 2020;104(5):1081-1084.

9. Vondran M, Rylski B, Berezowski M, et al. Preemptive Extracorporeal Life Support for Surgical Treatment of Severe Constrictive Pericarditis. Ann Thorac Surg. 2019;108(5):1376-1381. 
10. Fang L, Yu G, Huang J, et al. Predictors of postoperative complication and prolonged intensive care unit stay after complete pericardiectomy in tuberculous constrictive pericarditis. J Cardiothorac Surg. 2020;15(1):148.

11. Ahmad H, Porter R, Yusuff $\mathrm{H}$, et al. Extracorporeal membrane oxygenation for right ventricular failure following pericardiectomy. Eur J Cardiothorac Surg. 2019;56(3):625-626.

12. Rupprecht L, Putz C, Flörchinger B, et al. Pericardiectomy for Constrictive Pericarditis: An Institution's 21 Years Experience. Thorac Cardiovasc Surg. 2018;66(8):645-650.

13. Chang SA, Oh JK. Constrictive Pericarditis: A Medical or Surgical Disease?. J Cardiovasc Imaging. 2019;27(3):178-186.

14. Napolitano G, Pressacco J, Paquet E. Imaging features of constrictive pericarditis: beyond pericardial thickening. Can Assoc Radiol J. 2009;60(1):40-46.

15. Welch TD, Oh JK. Constrictive Pericarditis. Cardiol Clin. 2017;35(4):539-549.

16. Welch TD, Oh JK. Constrictive pericarditis: old disease, new approaches. Curr Cardiol Rep. 2015;17(4):20.

17. Welch TD. Constrictive pericarditis: diagnosis, management and clinical outcomes. Heart. 2018;104(9):725-731.

18. Miranda WR, Oh JK. Constrictive Pericarditis: A Practical Clinical Approach. Prog Cardiovasc Dis. 2017;59(4):369-379.

19. Hemmati P, Greason KL, Schaff HV. Contemporary Techniques of Pericardiectomy for Pericardial Disease. Cardiol Clin. 2017;35(4):559-566.

20. Unai S, Johnston DR. Radical Pericardiectomy for Pericardial Diseases. Curr Cardiol Rep. 2019;21(2):6.

21. Zhu P, Mai M, Wu R, et al. Pericardiectomy for constrictive pericarditis: single-center experience in China. J Cardiothorac Surg. 2015;10:34.

22. Yunfei L, Tao L, Yongjun Q. Re-pericardiectomy for recurrent chronic constrictive pericarditis: left anterolateral thoracotomy is a better approach. J Cardiothorac Surg. 2019;14(1):152.

23. Biçer $\mathrm{M}$, Özdemir B, Kan I, et al. Long-term outcomes of pericardiectomy for constrictive pericarditis. J Cardiothorac Surg. 2015;10:177.

24. Lin $Y$, Zhou M, Xiao J, et al. Treating constrictive pericarditis in a chinese single-center study: a fiveyear experience. Ann Thorac Surg. 2012;94(4):1235-1240.

25. Nozohoor S, Johansson M, Koul B, et al. Radical pericardiectomy for chronic constrictive pericarditis. J Card Surg. 2018;33(6):301-307.

26. Ghavidel AA, Gholampour M, Kyavar M, et al. Constrictive pericarditis treated by surgery. Tex Heart Inst J. 2012;39(2):199-205.

27. Busch C, Penov K, Amorim PA, et al. Risk factors for mortality after pericardiectomy for chronic constrictive pericarditis in a large single-centre cohort. Eur J Cardiothorac Surg. 2015;48(6):e110e116. 
28. Ertog SC, Thambidorai SK, Parakh K, et al. Constrictive pericarditis: etiology and cause-specific survival after pericardiectomy. J Am Coll Cardiol 2004;43(8):1445-52.

\section{Figures}

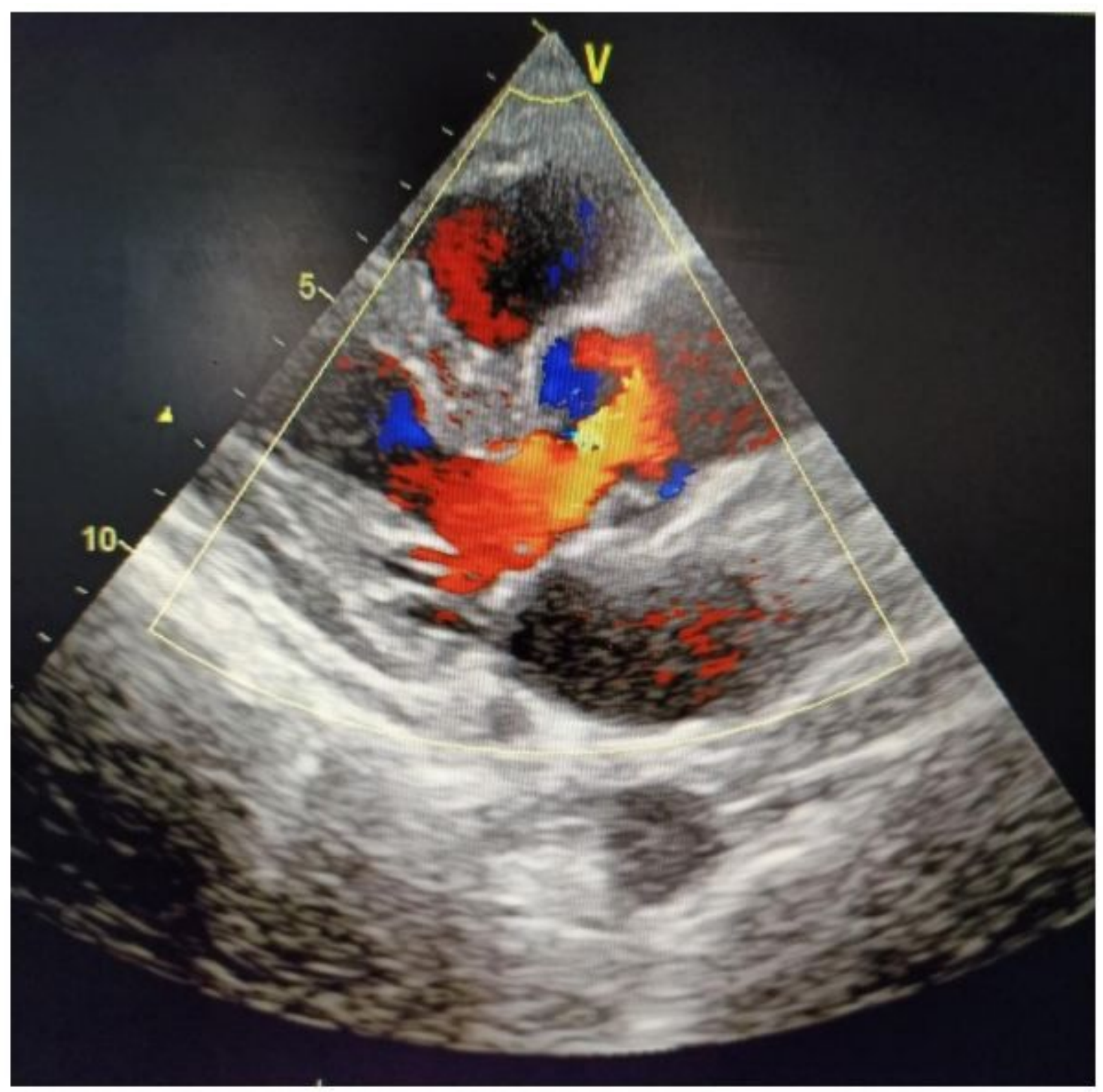

\section{Figure 1}

Transthoracic echocardiography showing the thickened pericardium 


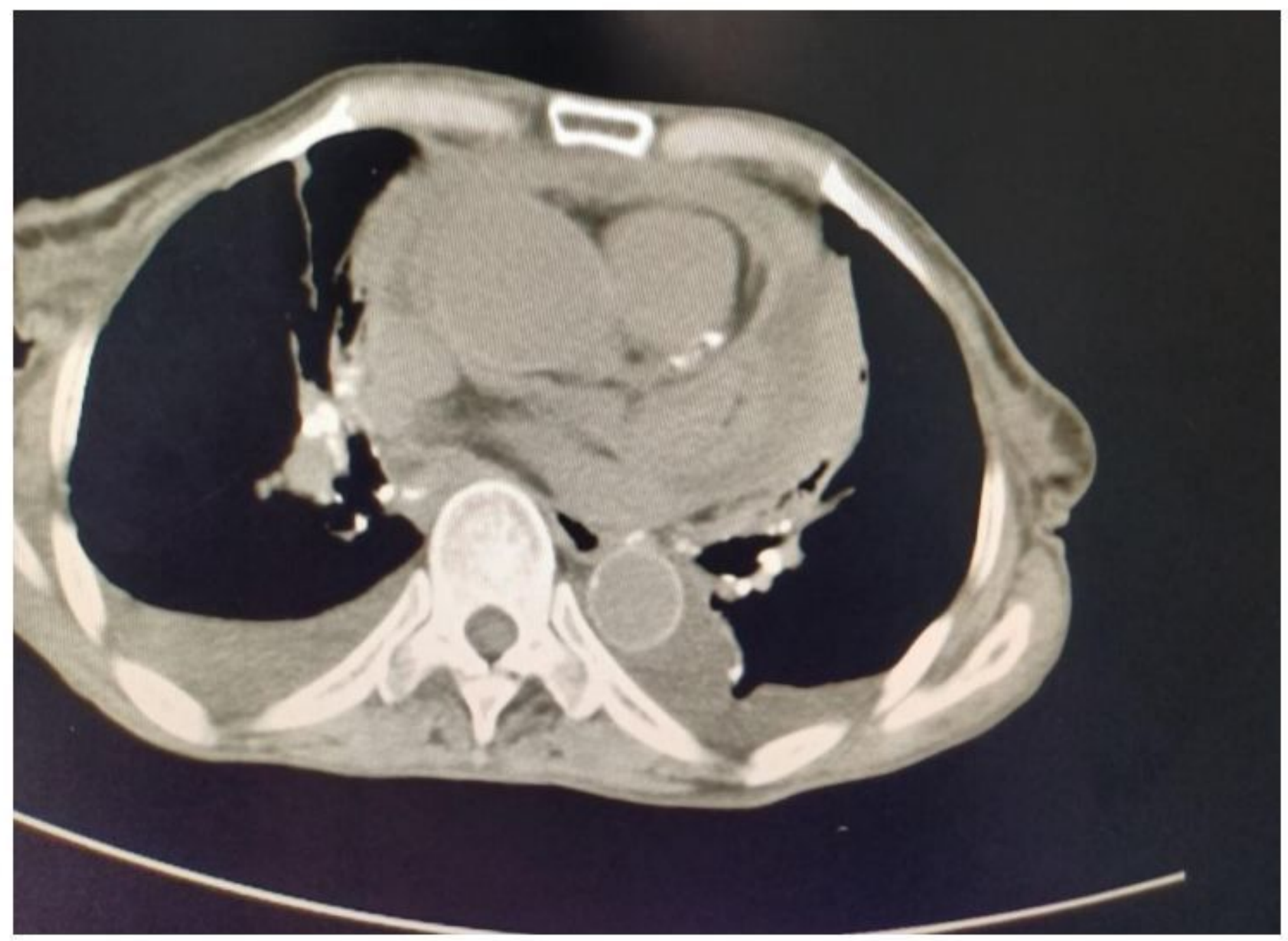

Figure 2

Chest computed tomographic scan showing the significantly thickened pericardium. 


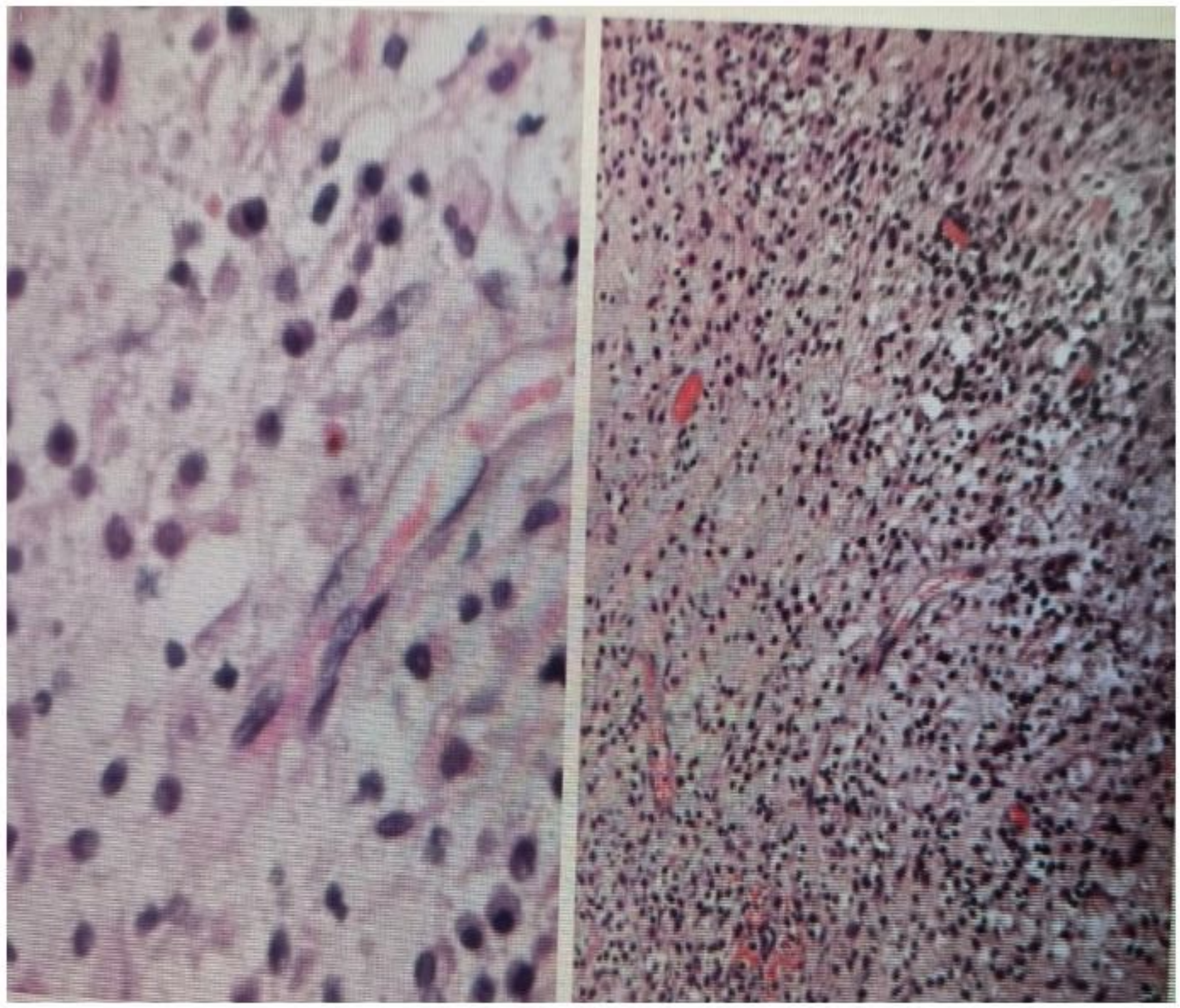

\section{Figure 3}

Histopathologic studies of pericardum tissue from patients showing the characteristic histopathologic features of tuberculosis including typical granuloma and caseous necrosis. 


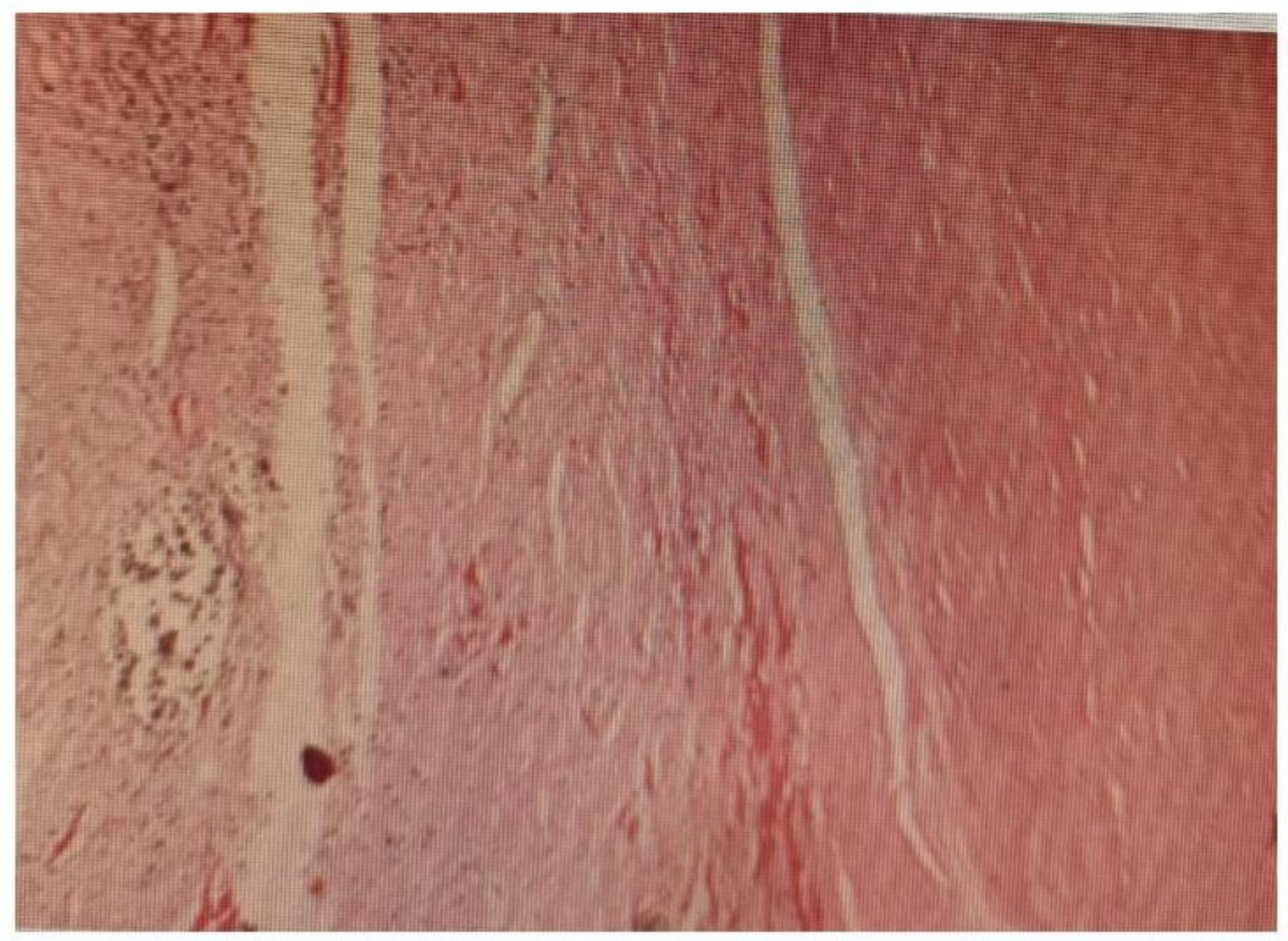

\section{Figure 4}

Histopathologic studies of pericardum tissue from patients showing the histopathologic findings of chronic nonspecific inflammatory changes. 